\title{
Dealing with the past: The youth and post-war recovery in southern Sudan
}

\section{Shastry Njeru*}

\begin{abstract}
The role of young people in times of conflict and their potential within postconflict recovery are phenomenal. If efforts are not made to reintegrate the youth and access their potential in Southern Sudan, post-conflict recovery will have limited success. Disarmament, Demobilisation and Reintegration (DDR) programmes are the primary instruments that external actors can apply to induce spoilers of peace into the peace process or to reduce their threat to microlevel dynamism and to promote creative life strategies of war-affected individuals who are primary stake-holders in the nation-building process. By providing for the educational, vocational and other social needs of young ex-combatants and enabling them to gain skills and competences that facilitate their economic and social integration, the youths may be brought to a point where they find the alternative of returning to combat unattractive. In meeting the needs of the youths, it is important not to homogenise them as either security threats or passive victims needing special sympathy, but as complex and heterogeneous
\end{abstract}

* Shastry Njeru is a Transitional justice Manager at the Zimbabwe Human Rights NGO Forum in Zimbabwe. Before that, he worked as a school teacher, civil servant and university lecturer. He is currently enrolled as a Ph.D. candidate at the University of KwaZulu-Natal. His interests are in post-conflict recovery and dealing with the past. 


\section{Shastry Njeru}

individuals with multiple skills, aspirations and limitations of their own. Effective DDR programming must factor in the wartime history of individuals. Dealing with the past strategies in southern Sudan should acknowledge and build on the youths' potential as the starting point.

\section{Introduction: Post-war frustrations}

The challenges are many, including massive destruction by war and slow reconstruction after the Comprehensive Peace Agreement. There are limited educational opportunities and insecurity is growing again (Atari et al. 2010) in most parts of Southern Sudan. The insecurity is attributed to the people's frustration due to unemployment and irregular payment of government employees. Instances of cattle raiding and tribal conflicts have increased and have caused about 2000 deaths and the displacement of about 250000 people (Atari et al. 2010:11). There are demands for the Government of Southern Sudan to improve the situation through the creation of new livelihood options to supplement traditional livelihood models.

In many cities people are waiting for the 'benefits of peace' from a government that is institutionally underdeveloped. The problems of 'liability of newness, lack of capacity, limited investment in basic infrastructure, including schools and allegations of corruption' (Atari et al. 2010:11) are writ large. People are frustrated by what they perceive to be limited and slow change. The growing demands from many returnees and ex-combatants show that technical, vocational and entrepreneurial capacity is needed for development and reconstruction, as well as skills for the economy to be competitive and to grow. Such agitation is a sign that southern Sudan needs to control the situation before it gets out of hand.

\section{The long war and the long-term damage it has done}

War and peace benefit from the youth in many ways. In peacetime the youth provide the reservoir of any country's energy to grapple with its present circumstances and future challenges. The youth forms the basis for the continuous reproduction and the productive potential of any society. A country without youth may be threatened with extinction. Likewise, the youth provides 


\section{Dealing with the past: The youth and post-war recovery in southern Sudan}

the mainstay of the fighting personnel in any nation in times of war. Children, as young as nine years, can be considered old enough to fight in some countries. Peters et al. (2003) notice the prevalence of young people both as fighters and victims of war. Young people are considered daring and having energy, but also account for heavy casualties of war because of battle-related wounds, malnutrition and disease.

The escalation of the war in the southern Sudan made the area ungovernable and caused it to be a fishing ground for rebel movements that all formed part of the Great Lakes problem. The Sudanese People's Liberation Movement and Army controlled the area, the Lord's Resistance Army for Uganda operated from the forests in the southern tip of the territory, and various Democratic Republic of the Congo militias crossed into the southern Sudan without much restraint. Splinter groups of armed non-state actors also operated in southern Sudan. All of them harvested children and youths and committed various atrocities using these young people.

It is alleged that rebel movements in Africa employ terror tactics to recruit children into their armies (Peters et al. 2003). Children are also violently abducted or pulled from their classrooms by armed people, leaving them with memories that will remain etched on their minds forever. Some children were forced to join the military because of the dire circumstances - with few alternatives - in which they found themselves at home. Poverty, lack of food, the need for power and protection, and the lack of opportunities for vocational training and education often forced children into soldiering. It was violent recruitment/abduction, the need to revenge, a need for shelter and/or community, or simply lies that have led them into participating in the war (Edwards 2008) and swelling the ranks of the belligerents. Whatever the method used, children ended up armed with lethal weapons and perpetrating violence because once recruited or abducted, children are expected to behave as adults. With the aid of drugs and heated feelings of rage and hate, children committed untold acts of terror and violence ${ }^{1}$ even in their own communities. It is also alleged that their commanders routinely abused these children in an effort to harden them. There seems to have

1 See the movie 'Blood Diamonds' directed by Edward Zwick. 


\section{Shastry Njeru}

been a deliberate policy to de-humanise the children and turn them into killing machines (Honwana 2002).

It has been argued that the prevalence of violence in Africa is due to 'youth crisis' or 'youth bulges' (Heinsohn 2009). In comparison with other continents, Africa has the youngest population. Youth constitutes a major percentage of the continent's population which it cannot absorb in its schools and places of work. In some places these institutions are inadequate or non-existent. Africa has excess youths without access to schooling or gainful employment, ready to heed the call to bear arms for spurious ideological or ethnic reasons. Such youths are easily off-loaded on any viable militia or government for use in violence.

$58 \%$ of the population in southern Sudan is under the age of 18 years (Watchlist 2003). In the most vulnerable areas of southern Sudan - Bahr el Gazal, Eastern Equatoria, Western Equatoria, and Upper Nile - about 2,6 million children are under the age of 18 (Watchlist 2003). Lack of job opportunities and education has increased disaffection and violence in these areas. Pursuant of the 'greed and violence' school (Collier 2004), the presence of such large numbers of uneducated young people and/or the prevalence of lootable natural resources like diamonds, have/has been a better predictor of civil war than the ethnic argument or ideological reason. Africa is endowed with both.

Some 'peaceful countries' experience episodes of violence, and in some cases this violence claims more lives than a known civil war. Eastern Nigeria has experienced violent confrontation between criminals, vigilantes and state authorities comparable to the 'warlord violence in Liberia' (Reno 1988). Still, the lives annually lost by murder in South Africa are more than what civil war in Sierra Leone claimed in a single year (Peters at al 2003). With regard to South Africa, Marks (2001) acknowledges the deep involvement of the former antiapartheid activists in vigilante groups and gangsters, but is quick to diffuse the links between the youth's involvement in fighting apartheid and the later criminal behaviour. However, the mobilisation of the youth to meet the requirements of the armies and criminal gangs is undisputed. In Zimbabwe, the youth militia (Green Bombers) recruited by the ZANU-PF party have been at the forefront of gross violations of human rights. 


\section{Dealing with the past: The youth and post-war recovery in southern Sudan}

The Comprehensive Peace Agreement (CPA) of 2005 between the government and rebel movements in Sudan presented an opportunity for a lasting peace after 22 years of war in southern Sudan. More than 100000 youths and children were involved in the war directly or indirectly. A relapse into civil war is likely if the needs of youths are not addressed. For a very long time wars have been viewed as the art of statecraft by the belligerents in Sudan. They base their perspective on the empirical fact that states in Europe have evolved as a result of war, and on the opinion that war can be liberating. Southern Sudan rebel movements held beliefs that they were fighting to liberate themselves from the Arab domination. In all the cases of warfare, whether it is legitimate war of self-defence or unprovoked wars, the burden of fighting is borne by the youths. Likewise, the burden of peace must weigh heavily on their shoulders as well.

Children and youths have fought in most of the wars waged on African soil. There are accounts of children fighting wars in the Democratic Republic of the Congo, Liberia, and Sierra Leone, children committing the bulk of the genocide in Rwanda and some committing war crimes in northern Uganda and in Mozambique. There are also reports about the extent to which the Sudanese Peoples' Liberation Army (SPLA) recruited children and youths. Most of these would have been abducted or press-ganged into the armies (Marks 2001). These children committed many unimaginable atrocities during the times of war. Some of the children are severely traumatised because of what they did. At the instructions of their adult superiors, some executed comrades who had become war-weary and attempted to desert and/or suspected sell-outs. This process, considered as initiation into brutality or as protracting war, has often affected their DDR, making reunion between children and their parents or societies after the war a most difficult process.

For the 22 years that southern Sudan has been at war, normal life of children was systematically disrupted. War violates every right of the child. It completely disrupts their infrastructure of social support and networks. It is estimated that altogether about 77 million children were affected by a natural disaster or war each year between 1991 and 2000 world wide, and about 75 million were from developing countries (Jabry 2002). War systemically alters the trajectories of hundreds of thousands of young lives. Without the guidance and nurturing 


\section{Shastry Njeru}

elements of adult supervision, many children are left to the most difficult task of fending for themselves (Edwards 2008). In most war cases, children are left abandoned or orphaned, with all the difficulties of finding their own means of survival. In extreme cases children are traumatised as a result of the violence surrounding them. The killing, death, disappearance, detention or flight of parents and caregivers results in hundreds of thousands of child-headed households and tens of thousands of street-children, orphans and child-headed households, some headed by children as young as eight years of age (Mazurana and Carlson 2006).

The nature and methods of armed conflict mean that the fighting takes place in civilians' communities, villages, fields and homes, thus sharply increasing children's risk of harm (Mazurana and Carlson 2006). During the war some children are coerced into performing horrendous acts, often in their own communities, in order to survive. Drug trafficking, grave digging, executions, transporting equipment can be forced upon defenceless children. A girl-child, because of her biological disposition, is subjected to severe humiliation and abuse (InterAction Task Force 2002). It is widely noted that prostitution increases during the times of war, and that the presence of international peacekeepers actually leads to the involvement of more prostitutes (Hilgate 2004). Sexual exploitation is devastating for children as it leads to pregnancy, diseases and trauma. Society, on the other hand, ostracises young mothers impregnated by armed people or peacekeepers for giving birth to 'UN children'. This secondary stigmatisation is enduring since it is continually reinforced by the society that holds particular values about chastity and marriage.

Once recruited, girl soldiers are disproportionately ill-treated. They are subjected to gender-based and sexual violence, and are forced into marrying commanders. The Lord's Resistance Army of Northern Uganda is known for this problem. Children subjected to these violations of human rights endure various reproductive health problems like sexually transmitted diseases, early pregnancies, unhealthy child deliveries, and the trauma associated with multiple rapes. They carry these social problems alone into their post-conflict life. The end of the war often does not bring them better hopes, but only the disdain of the society. 


\section{Dealing with the past: The youth and post-war recovery in southern Sudan}

When the war is over, the memories of the past cling to the minds of the children, haunting them on a daily basis. It is the children who remain icons of the disaster. Pot bellied children with limbs like sticks roam the streets, teen prostitutes lurk in the dark corners of the capital cities, and children clamber over the rubble of destroyed towns trying to salvage something. Without proper therapy, the nuances of the violent past continue to replay in front of the children well after the war. Long-term effects of war on children have been documented. Levy and Sidel (2009) account for the 'long term hostility, functional disability, anxiety, problems with relationships, somatisation (hysteria) and Post-Traumatic Stress Disorder (PTSD)' in children. Loss of motivation has been documented also as an effect in some grown-up children. According to Marshall (2004), 'women and children account for almost $80 \%$ of the casualties of conflict and war, as well as $80 \%$ of the 40 million people in world who are now refugees from their homes'

Given this account of the life of the young people during war, this paper argues that serious care has to be taken during the DDR in order to transform the lives of children who were soldiers or were directly affected by the war. Children will remain children despite their chequered history which is replete with crime and murder. Rehabilitating them will benefit the greatest part of the society of which they are part. Therefore post-conflict recovery should concentrate on protecting the child soldier/victim/survivor for the following reasons among other things:

1. The adult society is culpable for recruiting the child into crime and murder associated with the wars that the youth did not understand. In most cases these children did not choose the life of a rebel. They were either abducted, gang pressed or cheated into enlisting.

2. Because the future lies with the children, it makes good investment sense to commit resources to their rehabilitation and transformation.

3. Concerted youth programmes will assist children in unlearning the war life and help them to see more value in civilian life than in war life.

4. Commitment to transforming the lives of the youths will cultivate in them a commitment to the lives of others - the brother's keeper principle. All children can be trained in this commitment. 


\section{Shastry Njeru}

A commitment to transforming the lives of children in southern Sudan is like the proverbial hammering of a sword into a ploughshare. There were about 100 000 children in southern Sudan who were directly or indirectly affected by the war in the 22 years of the conflict's history (Deng 2003). It is further estimated that about 39000 children, less than 18 years of age, have been conscripted into the army over the years in southern Sudan and that a similar number was abducted by the government-led militias for forced labour or slavery. Some of the children served in the rebel forces as soldiers, slaves and porters, or as wives. In the streets of Khartoum and the scattered refugee camps there were children and youths who were dislocated from their parents, the so-called 'lost boys' of Sudan. Some of the children ended up in prostitution and petty crime. But the majority of them were in refugee camps. Some of the children were in camps in neighbouring countries where they have sought refuge during the years of strife.

\section{Dealing with the past to create a future - especially for the youth}

No approach to dealing with the past would be complete without taking the context of the process into account. The end of any conflict represents a complete turn-around in perspective. Ideally, the structural and underlying causes of the conflict must be eliminated, solid and efficient institutions must emerge, and they must serve the entire population. Recognisable and legitimate formal structures must be built up to allow the opinions and interests of the various actors in society to find expression without the use of violence. The culture of conflict, the 'metaconflict', must give way to a culture of negotiation; the culture of distrust toward institutions must yield to one of confidence. Transitional justice is often the path of choice in dealing with the past since the end of the Cold War.

Dealing with the past is closely bound up with the potential contribution of the past to the necessary and fragile reconstruction of an entire society. In dealing with the past, the choices are often dictated by complex power balances between the belligerents themselves, between the belligerents and 'civil alliances for peace', and between all these involved parties and external actors. These power 


\section{Dealing with the past: The youth and post-war recovery in southern Sudan}

balances depend on the strategic importance given to the conflict or to the region concerned, and to whether there was a total or partial regime collapse. Dealing with the past must help transform the culture of conflict, both materially and conceptually. On the one hand, through its modalities, the process should avert any repetition of violent events, and especially of the human rights violations that occurred during the conflict. It should also aim at repairing the social and material damage caused and at setting up the institutional mechanisms for good governance, particularly in the legal field, based on the observance of human rights and democratic rules. On the other hand, it must also help transform the normative and functional culture of violence into a democratic culture of peace and civil conflict management. Dealing with the past plays a crucial role in depolarising the society. The process should foster a sense of national belonging or unity and should contribute to building structures and relations based on trust. This brings us directly to the subject of the reconciliation process and national healing.

Thus, dealing with the past in the framework of conflict transformation encompasses a range of activities to promote peace and strengthen human security. Activities should have a clearly forward-looking orientation, and should work to bring about a reconciled and democratic society that is capable of managing its conflicts peacefully. Good examples are:

- Improving the knowledge about and the observance of human rights, international humanitarian law, and the fight against impunity;

- Building up the skills and action capabilities of non-state actors that can contribute to civil peace promotion;

- Enhancing the media and educational vehicles for peace promotion (Massard 2004:10).

Post-war reconstruction is a broad, deliberate and comprehensive programme of rebuilding lives and institutions to restore them to their pre-war levels or better. The major objective of post-war reconstruction is not to make people forget about their war but to learn from it. In a post-war recovery programme, societies divided by war will take time to reflect about the war and its negative 


\section{Shastry Njeru}

effects as a starting point for a new, productive and reconciled life. As such this period should ensure that all war institutions and symbolisms are destroyed and new ways of life are learnt.

Post-war reconstruction programmes should be implemented in a way which recognises that the greatest victims of the war were children and young people. Actually, children have been 'targeted as a matter of strategy' (Massard 2004:11). The nature of the war brings about that children suffer concurrently with their relatives. When the war effort demands contributions from citizens in the form of call-ups or increased taxation, the children and the youth become the collateral. As the war intensifies the children miss school because their schools were destroyed or their teachers were killed or fled. The children suffer malnutrition because the food stores were looted, or farms were bombed or mined to such an extent that they ceased to be arable to produce food. Diseases that could have been controlled through immunisation claim or cripple some children because the hospitals were looted of drugs and essentials; and in most cases the medical staff was driven out or killed. Increasingly, public places like schools, hospitals, markets and even refugee camps become battlefields. As a result some children are orphaned early in life because their parents got killed for holding a different political view or belonging to a wrong religion or skin colour. Therefore, addressing such challenges affecting the youths and children in a post-conflict society must be a national priority.

\section{Helping to transform the lives of young ex-combatants - by providing in their needs}

\subsection{Educational needs - especially in rural areas}

UNICEF (United Nations International Children's Emergency Fund) reported that one in fifty children in southern Sudan completes primary education. 'After 21 years of war, southern Sudan ranks as the worst place in the world for many key indicators of women and children's well-being, including its rates of chronic malnutrition, primary school completion, immunisation and antenatal care' (Moszynski 2004:13). The education system in Sudan has not been spared by the long civil war that has characteristically led to the exclusion 
and political vulnerability of southern Sudan (Deng 2003). It is not surprising that the education system has been a key tool used by the northern ruling elite for perpetuating socio-economic and political marginalisation of the majority rural communities and southern Sudanese in particular. Yet it is in southern Sudan where the Nile-based civilisation flourished (Nubia, Kush and Fanj), predating Arabic and Christian presence in Sudan (Deng 2003). The Arabic and the British rulers did not recognise this civilisation and eventually marginalised it. This has motivated the civil war.

The British left a legacy of underdevelopment during their years of administration of the Condominium (1898-1955). Lesch (1998) argued that the British rulers entrusted Christian missionaries to provide moral guidance, which they perceived to be a greater need in the south than economic development. Additionally, 'they sealed off' southern Sudan from the slavery of the north through the Closed District Order in 1922 (Deng 2003). A new language policy was introduced which banished the speaking or learning of Arabic in the southern Sudan with the intention of linking the territory with British East Africa. These British policies did not foster economic and social development in the south but widened the already substantial gap with the north (Deng 2003). The limited number of missionary schools did not meet the education needs in the south and as late as the 1940s, government schools in the south included only a few elementary schools, two intermediate schools, one teacher training centre, one commercial school and one senior secondary school (Deng 1995:86).

Table 1: British colonial legacy: Level of access to education by 1960

Number of education facilities (streams, schools and universities)

\begin{tabular}{|l|r|r|r|}
\hline Level of Education & North & South & Total \\
\hline Intermediate Streams (Boys) & 194 & $20(9 \%)$ & 214 \\
\hline Intermediate Streams (Girls) & 55 & $1(2 \%)$ & 56 \\
\hline Secondary School Streams (Boys) & 49 & $2(4 \%)$ & 51 \\
\hline Secondary School Streams (Girls) & 14 & $0(0 \%)$ & 14 \\
\hline Commercial Secondary Schools & 2 & $1(33 \%)$ & 3 \\
\hline Technical Secondary Schools & 3 & $0(0 \%)$ & 3 \\
\hline Universities & 4 & $0(0 \%)$ & 4 \\
\hline Khartoum University students & 1156 & $60(5 \%)$ & 1216 \\
\hline
\end{tabular}

Source: Oduho and Deng 1963 


\section{Shastry Njeru}

The legacy of unequal access to education was deepened in the post-independence era with the north commanding a far greater share of education facilities than the southern Sudan. The table below highlights the case of inequality.

Table 2: Level of access to education during the inter-war period, 1972-83 Number of education facilities and population of students

\begin{tabular}{|l|r|r|r|}
\hline Level of Education & North & South & Total \\
\hline Primary Pupils (in 000) & $1349(90 \%)$ & $143(10 \%)$ & 1492 \\
\hline Primary Schools & $5343(87 \%)$ & $809(13 \%)$ & 6152 \\
\hline Primary Teachers & $39188(92 \%)$ & $3432(8 \%)$ & 42620 \\
\hline Pupil Teacher Ratio & $1378(93 \%)$ & $96(7 \%)$ & 1474 \\
\hline Intermediate Schools & $199(93 \%)$ & $15(7 \%)$ & 214 \\
\hline Secondary Schools & $3499(99 \%)$ & $29(1 \%)$ & 3528 \\
\hline Universities Admissions in 1983 & 34 & 42 & \\
\hline
\end{tabular}

Source: Yongo-Bure 1993

Deng (2003:6) writes concerning this conspicuous inequality:

With population of 20 million during the inter-war period, the primary school enrolment rate was about 40 per cent in the north but less than 12 per cent in the south. Also while pupils' teacher ratio was about 34 in the north, it was 42 in the south. In comparison to its size of population, the inequality in the level of access to education at all levels was significant and striking and clearly indicates that the central government did not exert effort to narrow such inequality between north and south during the brief period of relative peace.

Only one in 50 children completes primary education in the south, which is thought to be 'the lowest rate in the world', and only one in four adults (one 


\section{Dealing with the past: The youth and post-war recovery in southern Sudan}

in 10 women) are literate (Moszynski 2004). Yongo-Bure suggested that it is this inequality that prompted rebellion of the southern Sudan. These profound horizontal inequalities generated a sense of frustration and feeling of injustice and exclusion that eventually led people in the south to resort again to armed struggle in 1982 (Yongo-Bure 1993).

Education in southern Sudan suffered heavily during the period of complex emergency. By 1993 there was very limited support to education in southern Sudan. After the emergency the situation has not improved either. Most of the schools remain 'bush schools' with no permanent buildings of brick under tin. The 'bush schools' are community initiatives to replace about 800 schools destroyed by war. The syllabi have not been improved or coordinated, with many schools adopting Kenyan or Ugandan curricula (Deng 2003). This introduces a lot of ideological inconsistencies for both the children and the country since the 'spirit' of a society is perpetuated in its education system. Southern Sudan has no such starting point.

Teachers in southern Sudan are poorly trained with only 7 per cent having received college training, while the rest either have some in-service training (48 per cent) or are completely untrained (45 per cent) (UNICEF/Open Learning System 2002:4). Female teachers constitute only 7 per cent of all the teachers. Besides the acute shortage of trained teachers, the schools are poorly equipped with teaching facilities and teacher's guidebooks (Deng 2003).

Schools are the most valued possessions of the youth. The collapse of the educational structures has often fuelled violence in some parts of Africa. For the youth, formal education and job opportunities are the key to a good life, although there is no direct correlation between having education and a good job or a successful life (Peters et al. 2003). In a post-war setting, different categories of young people can be distinguished on the basis of their academic history. These range from young people with very little or no education, to young people who dropped out of primary or secondary school either before the war or as a result of it, to young people who were able to finish their education (Peters et al. 2003). 


\section{Shastry Njeru}

The long years spent in waging war force many young people to miss out a lot. In most cases school systems were destroyed, teachers got killed and some fled. Children with no educational future often find joining the military groups their only option. In post-conflict recovery programmes it is important to develop specially designed catch-up programmes to meet the special needs of those affected by the war. Most importantly, there is a need to develop curricula that are of a problem-solving nature. Mass schools may not be the best as these may end up mass-producing educated youths who cannot be absorbed in the nascent industry. In fact it is the curricula that need to be relevant to the youth in the post-conflict situations.

To attract many youths back into schools entails a lot of sacrifice. School life needs a certain discipline which some of the children cannot stand due to their independent life as combatants or street children. Very few children, particularly those who lost their parents or guardians, will be willing to part with the few monetary resources they may have. The government and local authorities need to initiate waivers of school fees to the youths until they are well entrenched into the school systems to continue on their own. While the problem of who will meet the cost of their education becomes even more pressing in the era of reduced official donor support, the schools need to be rebuilt, books and provisions are needed for schools to function properly and salaries for teachers need to be paid to keep them in class. The overall danger is that the children or youths will certainly drop out of school when the opportunity for free education comes to an end, and will then find refuge in the willing arms of a viable militia group. The post-conflict recovery programmes can therefore not afford to neglect the crucial component of the future of the country - the youths and children.

Many schools are looted and destroyed during wars, and need to be rebuilt. Money to rebuild destroyed schools or put up new ones altogether may be limited. Qualified teachers may not be too keen to teach in the remote areas where there are no provisions comparable to schools in urban areas and where security is weak. There is need to provide special incentives for teachers to prefer rural life more. School authorities need to provide good water, sanitation and accommodation for the teachers to stay. More attention should be given to schools in rural areas. Some regions are so poor that children and youth 


\section{Dealing with the past: The youth and post-war recovery in southern Sudan}

will not (or cannot) attend school unless food is provided. Supplementary feeding programmes may be the best solution to keep the hungry children motivated, focused and looking forward to come to school the following day. These challenges affect the resumption of an education system after having been disrupted by civil wars. Notwithstanding all challenges, governments and donors need to support revamping the education system that can cater for the girl child's educational needs as well as for the youths whose educational backgrounds are diverse and have been affected by the conflict.

\subsection{Vocational needs in rural and urban situations}

Vocational training programmes provide functional skills of survival for many people who cannot be absorbed in formal school life, be it by age or by fate. There are youths who had joined the war when they were very young and grew to become adults fighting the war. The basic skill they have is firing a gun. These youths may also be married to their fellow combatants and have children to look after. The time may not be available for one to consider uninterrupted classroom education, and therefore vocational education must provide the necessary bridge with the working world. Vocational training offers shorter cycles that are easier for young people who have financial responsibilities of their family to attend to. Some of the ex-soldiers may just need to re-sharpen their skills, which were made obsolete by years in war. Others have been thrown into prostitution by war circumstances and a lack of skills. To lure these out of their vices, fully funded and relevant vocational training is needed in southern Sudan.

Richards et al. (1997) calculated that even without war, the growth in whitecollar jobs and jobs in the formal sector would not be enough to absorb all school graduates. In the post-war situations in most African countries, the only realistic option is self-employment in either a trade or a craft, particularly in the rural service sector. However, vocational training that trains a bunch of mechanics may not be the correct thing to do since after training the graduates will have to go back to their village where there are no cars to repair. The training has to be functional. There is need to provide skills needed in rural reconstruction, such as blacksmithing, sun-baked mud-brick manufacture, or improved food 


\section{Shastry Njeru}

processing (such as cassava milling), wood carving, stone craft, alongside the other skills like engineering or architecture that are needed in cities and towns.

Young people either have to be apprenticed to local artisans or trained in new skills. Non-governmental organisations (NGOs) are needed to experiment with forming rural reconstruction teams: e.g. training young ex-combatants to make spot improvements to rural roads, to build minor bridges and repair damaged culverts. These building brigades need to assist in repairing schools, hospitals and other institutions destroyed by war. But if ex-combatants are to continue with minor rural construction activities after contracts with donors have expired, they need not only technical skills, but also training in how to run a microbusiness (Deng 2003). This process imparts technical and business skills to the youths and also inculcates the responsibility to account for the past destruction through active reconstruction of the national and local infrastructure.

The conflict in southern Sudan has badly affected agriculture. Farms have been abandoned, burnt down or looted (Deng 2003). The period after the war has been characterised by serious shortages in seed, fertilisers and extension services. The country has been importing food. Slash-and-burn agriculture is practised in the region and most of the fields are overgrown with vegetation. A lot of labour is needed and the youths may provide this necessity. However, farming life is not their first preference (Deng 2003). But agriculture is the single sector that can absorb most of these poorly educated youths because of the low skills requirement and low cost labour availability.

To prop up rural development and agriculture, a land reform programme may be necessary for southern Sudan. The government needs to make land available to the youths for resettlement. Proper title deeds that can be collateralled must be given on land so that these youths may use them to secure credit from financial institutions. To enable the youths to stay on the land, an integrated system of business and agriculture need to be supported so that business will buy the farm produce and supply the necessary inputs. Rural enterprise must attract the youths with the prospect of bettering their life, and the youths may find the prospect of being involved in the entire value chain attractive. 


\section{Dealing with the past: The youth and post-war recovery in southern Sudan}

Prolonged conflict in southern Sudan drove many people from rural areas into near permanent squatter camps in towns. When the war came to an end, many people longed to go back home. In most cases, young people were not willing to go where they had no attachment with anyone, where homes had been destroyed, or where there was no running water or electricity. The youths who have stayed long in urban streets are reluctant to give all their energy to labour intensive semi-subsistence agriculture. It seems that former child combatants, even more than other groups of young people, hope to make their living in the city. This is partly due to the fact that some are afraid to return home to face their abusers or those they tormented during the war. This trauma is too great to carry. They would prefer to roam the streets and be 'free'.

Juba city and other towns in southern Sudan are developing. If the lease of stability were maintained, Juba would soon become a metropolis with vast attractions. It is crucial that urbanisation programmes taking place after the war balance rural needs and the growth of urban settlements. To satisfy the rural needs, the concept of growth points in rural areas needs to be tried as a way of balancing rural development and urban pull after the war. These growth points will reduce the draining of rural areas of its brightest minds that find alternative life in the cities around the country.

\subsection{Social needs - especially in urban settings}

The major vices that have destroyed the potential of the youths are violence, drug abuse, youth gangs, and prostitution. These are also the legacies of the violent past and the pastime for the unemployed. The youths often get on the drugs to temporarily overcome memories of the past. Drugs often lead to the sense of machismo and sexual carelessness, and cause the contracting of sexually transmitted diseases and HIV. It also leads to domestic violence and broken homes. Very few relatives may be willing to take in a demobilised violent youth with a record of violence and murder. More youths may find themselves with nowhere to go if this is not addressed. Violence is generally motivated by the ready availability of weapons of choice and arms caches, which some of the ex-combatants know about. In the post-war situation, it is often difficult to control the handling of weapons that end up in criminal hands. Stricter control 


\section{Shastry Njeru}

of the movement and acquisition of small arms and light weapons needs to be legislated for.

It seems that youths who were actually in combat and have become inured to it, also have the capacity to place the experience in a specific 'wartime limbo' (cf. Henriques 2002). Research on township violence in South Africa refutes the idea that there is any direct carry-over from the anti-apartheid struggle (Marks 2001). While the South African situation may be different, the weapons of war left behind in the Mozambican war have filtered into criminal syndicates in South Africa where they have been used to heist money transporting vehicles and commit other robberies. Unoccupied young Sudanese cannot escape what the youths in the industrial economy of South Africa have failed to escape. It can be worse considering the litany of weapons of choice sold at a give away price, e.g. at a price of a chicken one can get a functioning AK47 and a full magazine.

Deng (2003) argues that all efforts must be made to eliminate the marginalisation of the youths. The southern Sudan needs to realise that the youthful population outnumbers the adult population. Therefore, the youths are the biggest stakeholder or constituency in the affairs and direction the country will take. If marginalisation continues, so does the risk that the youths might one day be dissatisfied and re-recruited by militia organisers. It seems that any post-war increase in prostitution among girls and young women reflects the difficult situation many of them were in during war (in refugee camps, for instance, where they were preyed upon by soldiers and humanitarian workers). An increased number of marginalised youths become vulnerable to gang recruitment, prostitution and human trafficking where they are wasted and even killed. Designing correct policies that value the life of the youths can avert this.

Africa is a continent severely affected by the HIV and AIDS pandemic. The HIV/ AIDS condition is generally sexually transmitted, and is thus associated with the more sexually active part of the population. It is a condition biased towards younger people, though symptomatic AIDS may emerge a decade or more after infection (i.e. in young middle age). In Africa the spread of HIV/AIDS seems to be exacerbated, especially by the mobility and irregular sexual liaisons caused by war. The presence of militia combatants and peacekeeping forces may be 


\section{Dealing with the past: The youth and post-war recovery in southern Sudan}

regarded as vectors pointing in the directions where the infection is spreading (Peters et al. 2003). Data on HIV infection rates among militia forces in Africa are sparse, but there is every reason to suspect that in rebel groups where abductions and rape of young females are widespread, infection is high. In 2001, the World Health Organisation estimated that about 30000 under the age of 15 years in southern Sudan were HIV positive and that 62000 children had lost a parent to AIDS (Watchlist 2003). Intervention strategies deliberately targeting the children and youths need to be designed otherwise an entire generation, the backbone of a new country, can be wiped away.

NGOs and government departments should work together to stem the spread of the deficiency among the youths. The youths need to feel secure. However, they also need to be fully aware of the dangers of HIV and AIDS. First, awareness programmes have to be started targeting the youths and children. Secondly, problems of stigmatisation have to be overcome through concerted education and peer education. Thirdly, voluntary testing and counselling have to be promoted among the youths and school children. Where incidences of infection are reported, appropriate therapy and support have to follow to allow the victim to live positively. Where necessary, medical support should be made available to the sick in time to save their lives and at an affordable cost. Antiretroviral treatment prolongs life. Deliberate therapeutic interventions need to be instituted to deal with the mental health of those traumatised by war. Government and NGOs need to pool resources and skills to identify urban children who are violated and provide them with necessary treatment. A healthy youth will guarantee a healthy southern Sudan.

\section{Conclusion}

Southern Sudan has had twenty-two years of civil war. The war is over and reconstruction is overdue. Many returnees and ex-combatants are frustrated by lack of opportunities. Insecurity has increased as a result of tribal wars and cattle raids. On the menu of this transitioning society are many programmes: military and police reform, institutional development, security, government and the statecraft, health, demobilisation, and the list is obviously long. Practitioners and policy makers often get lost in this list on the post-conflict recovery 


\section{Shastry Njeru}

menu and lose sight of the children and youths who just but yesterday were the firebrands of their resistance or war. Ignoring them is throwing away the baby with the bath water. Post-conflict recovery has no deep foundation if it is not built on the youth. The democratic future of southern Sudan lies in the acknowledgement of the youths as direct victims of two decades of war and the legitimate beneficiaries of the peace. In light of the deep pockets of resources the future of southern Sudan needs, the youths have to be considered seriously as stakeholders in the quest for a durable peace in Sudan. If left out, southern Sudan will rumble again into the league of failed states in Africa. Through appropriate education, vocational training, agricultural programmes, urban policies, HIV and AIDS training, the youths will underwrite the future of southern Sudan. As the sage says, 'The life of the parent is in the blood of its children', so is southern Sudan. These are some of the ways this country can effectively deal with its past.

\section{Sources}

Atari, Dominic Odwa, Samer Abdenour, Kevin McKague and Roger Wager 2010. Technical, vocational and entrepreneurial capacities in southern Sudan: Assessment and opportunities. York, University Centre for Refugees Studies and Plan International Inc.

Collier, Paul 2000. Economic causes of civil conflict and their implication for policy. Washington, The World Bank.

Deng, Francis M. 1995. War of visions: conflict of identities in the Sudan. Washington, Brookings Institution.

Deng, Luka Biong 2003. Education in southern Sudan: War, status and challenges of achieving Education For All Goals. Paper prepared for UNESCO EFA (Education for all) Monitoring Report.

Edwards, Deirdre. 2003. The impact of war on children: A global perspective. Public Health and Social Justice, 510.

Heinsohn, Gunnar 2009. Ending the West's proxy war against Israel: Stop funding a Palestinian youth bulge, and the fighting will stop too. Available from: $<$ http://online.wsj.com/article/ NA_WSJ_PUB:SB123171179743471961.html> [Accessed 29 September 2009].

Henriques, P. 2002. Peace without reconciliation: War, peace and experience among the Iteso of east Uganda. Ph.D. thesis, Institute of Anthropology, University of Copenhagen.

Hilgate, Paul 2004. Peacekeepers and gender: DRC and Sierra Leone. Available from: <www. fwreview.org/text/FMR/15/02.htm> [Accessed 15 March 2009]. 


\section{Dealing with the past: The youth and post-war recovery in southern Sudan}

Honwana, Alcinda 2002. Negotiating post war identities: Child soldiers in Mozambique and Angola. In: Bond, G. and N. Gibson eds. Contested terrain and constructed categories. Boulder, CO, Westview Press.

InterAction Task Force 2002. Report on the prevention of sexual exploitation of displaced children. Available from: <www.interaction.org $>$ [Accessed 15 March 2009].

Jabry, Amer ed. 2002. Children in disasters: After the cameras have gone. A Report for Plan UK. London, Plan UK.

Lesch, Ann Mosely 1998. Sudan: Contested national identities. Oxford, James Currey.

Levy, B.S. and V.W. Sidel 2009. The social impact of war. Annual Review of Public Health, 3 (1-3).

Marks, Monique 2001. Young warriors: Youth politics, identity and violence in South Africa. Johannesburg, Witwatersrand University Press.

Marshal, Lucinda 2004. Unacceptable: The impact of war on women and children. Available from: <www.commondreams.org > [Accessed 12 December 2009].

Massard, Mor Bleeker 2004. Introduction and recommendations. In: Massard, Mor Bleeker and Jonathan Sisson, Dealing with the past: Critical issues, lessons learnt and challenges for future Swiss policy. Working Paper 2/2004.

Mazurana, Dyan and Khristopher Carlson 2006. The girl child and armed conflict: Recognizing and addressing grave violations of girls' human rights. United Nations Division for the Advancement of Women (DAW), in collaboration with UNICEF Expert Group Meeting on Elimination of all forms of discrimination and violence against the girl child, Florence, Italy, 25-28 September 2006.

Moszynski, Peter 2004. The civil war in southern Sudan and its effect on youth and children. London, BMJ Publishing Group Ltd.

Oduho, Joseph and William Deng 1963. The problem of the Southern Sudan. London, Oxford University Press

Peters, Krijn, Paul Richards and Koen Vlassenroot 2003. What happens to youth during and after wars? A preliminary review of literature on Africa and an assessment of the debate. RAWOO (Netherlands Development Assistance Research Council) Working Paper, October 2003.

Reno, William. 1998. Warlord politics and African states. London, Lynne Rienner.

Richards, Paul, Ibrahim Abdullah, Joseph Amara, Patrick Muana, Edward Stanley and James Vincent 1997. Reintegration of youths and ex-combatants: A study of the social and economic opportunity structure in Sierra Leone. Unpublished report for the Ministry of Relief, Rehabilitation and Re-integration. Government of Sierra Leone.

UNICEF/OLS (United Nations International Children's Emergency Fund / Operation Lifeline Sudan) 2000. Multiple Indicator Cluster Survey Results of Southern Sudan, 2000. Nairobi, UNICEF. 


\section{Shastry Njeru}

UNICEF/OLS 2002. School Baseline Assessment Report, Southern Sudan. Nairobi, UNICEF.

Watchlist 2003. On children and armed conflict. Available from: <http://www.watchlist.org/ reports/pdf/sudan.report.pdf> [Accessed 15 March 2009].

Yongo-Bure, Benaiah 1993. The underdevelopment of the Southern Sudan since independence. In: Daly, Martin and Ahmad Sikainga eds. Civil War in the Sudan. London, British Academic Press. 